\title{
A STUDY OF CORNEAL INJURIES IN RIMS TEACHING HOSPITAL
}

\section{Srividya $\mathrm{R}^{1}, \mathrm{H}$. Siddesh Kumar $* 2$.}

${ }^{1}$ Junior resident in dept. of ophthalmology, RIMS, Raichur, Karnataka, India.

${ }^{* 2}$ Associate professor in dept. of ophthalmology, RIMS, Raichur, Karnataka, India.

\section{ABSTRACT}

Corneal injuries remain an important cause of avoidable and, predominantly, monocular visual morbidity, the main strategy to prevent these injuries has been to educate people to identify high-risk situations and to take correct action to avoid danger. Present study conducted in the department of ophthalmology of Raichur institute of Medical sciences teaching Hospital, with 49 patients of ocular trauma above 14 years of either sex was subjected to slit lamp examination to ensure the cornea is involved the etiology of the injury was noted. Then the pattern of the corneal injury was studied under the slit lamp examination. The Prevalence of corneal blindness was $10.20 \%$ (5) were had corneal blindness in both eyes and $24.49 \%$ (12) were had corneal blindness in one eye in Raichur. The majority of corneal injuries are avoidable. Eye health promotion strategies are warranted to raise awareness about the causes and prevention of corneal blindness.

KEY WORDS: Flying/thrown objects, chemicals injuries, Corneal Injuries, and vegetable matter.

Address for correspondence: Dr. H. Siddesh Kumar, Associate professor in dept. of ophthalmology, RIMS, Raichur, Karnataka, India. E-Mail: drsiddesh@gmail.com, srividyador@gmail.com

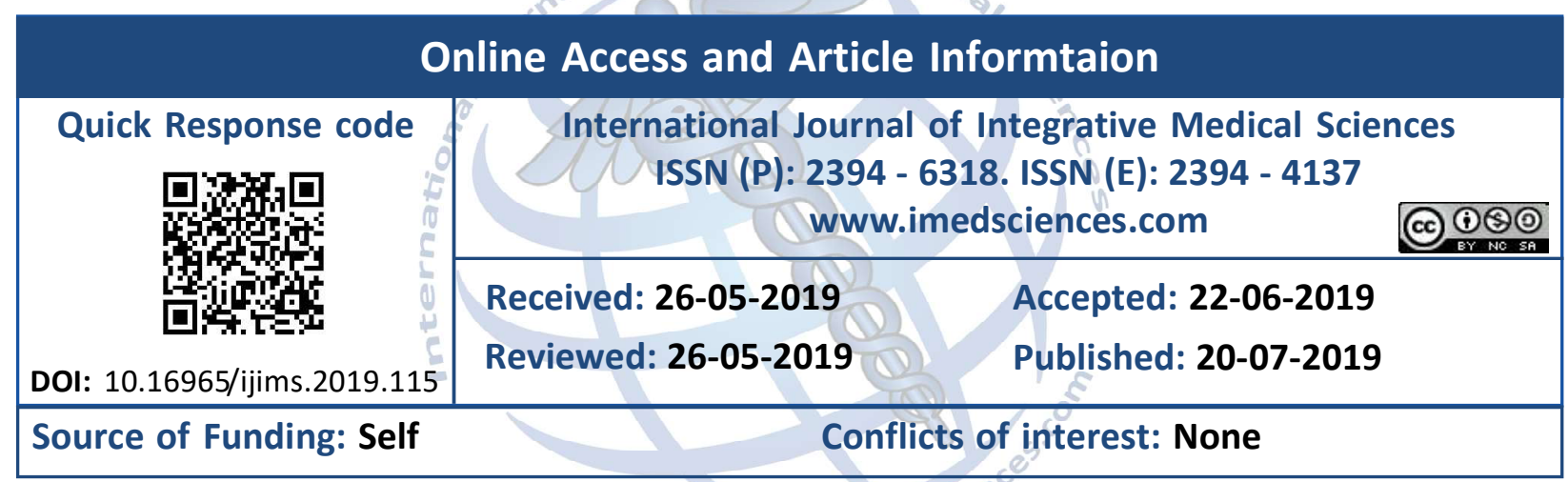

\section{INTRODUCTION}

Corneal injuries remain an important cause of avoidable and, predominantly, monocular visual morbidity (visual impairment and blindness) [1]. corneal injuries represent a major public health problem with poorly understood ramifications at both the individual and community levels. Changing life pattern, modernization, rapid industrialization and high-speed travel, wide and variable exposure to the surroundings are contributing factors in corneal trauma. Injuries to the eye due to delicacy of the ocular tissues a mild trauma may result in permanent blindness. Any of the ocular structures can be damaged in the case of closed globe injury. These lesions, often multiple, may appear immediately or in a delayed fashion. Classifications have been developed recently in order to better inform the patient of the visual prognosis. However, significant efforts are still needed, on the one hand, to assess and develop new therapies, and on the other hand, to implement effective policies to prevent ocular trauma [2]. Children at play, young men at work, in factories and construction sites, road side falls, high speed travel and road traffic accident, sport injuries, old age, fall upon projecting blunt objects and in a rural set up like India, agricultural based injuries are the causes of minor and severe blunt injuries.

Currently 45 million people worldwide who are bilaterally blind, of which 6 to 8 million are blind due to corneal disease. In some areas of Africa, nearly $90 \%$ Of total blindness is due to corneal pathology [3], prevalence varies from country to country depending on many factors, such as availability of general standards of eye care [4]. In India, there are approximately 6.8 million people who have corneal blindness with vision less than 6/60 in at least one eye, and of these, about 1 million have bilateral corneal blindness. 
If the present trend continues, it is expected that number of corneal blindness in India will increase to 8.4 million in 2010 and 10.6 million by 2020 [5].

Corneal blindness is responsible for 1.5 to 2 million new cases of monocular blindness every year in which ocular trauma and corneal ulceration are significant factors [6]. The epidemiological pattern and causative agents for suppurative corneal injuries varies significantly from country to country, and even from region to region within the same country. It is important to determine the "regional" aetiology within a given region for comprehensive strategy for the diagnosis and treatment of corneal injuries [7]. In a vast agricultural country like India, particularly where primary health care and referral systems are weak, minor eye injuries sustained in agricultural farms often lead to infectious corneal ulceration and loss of vision [8]. With the knowledge of circumstances of injury, their nature and damage caused, early appropriate management can be taken, and preventive measures may be advised. Hence, the main strategy to prevent these injuries has been to educate people to identify high-risk situations and to take correct action to avoid danger.

\section{MATERIALS AND METHODS}

Present study conducted in the department of ophthalmology of Raichur institute of Medical sciences teaching Hospital, with both the inpatient and outpatient department of ophthalmology of Raichur institute of Medical sciences teaching Hospital. All patients of ocular trauma above 14 years of either sex was subjected to slit lamp examination to ensure corneal involvement. Once the cornea is involved the etiology of the injury was noted. Then the pattern of the corneal injuries was studied under the slit lamp examination. Informed consent was obtained after informing the study subjects the details of the procedure. After initial examination the cornea was stained with $2 \%$ fluoresce in strip paper and examined under the slit lamp with blue light to note the type of corneal injury in the form of abrasions of epithelium, stroma and others. After establishing a diagnosis, the patient was subjected to keratometry, A scan, B scan ultrasound or anterior segment Optical Coherence Tomography if required. Patients aged below 14 years and Ocular trauma where cornea is uninvolved patients were excluded from the study. After noting all the details, the patient was given treatment as needed for the specific type of corneal injury. The patients were followed up on day 1 , day 3 , after 15 days, after 1 month and after 3 months.

They were examined under the slit lamp and staining would be done if required. The improvement or the opacification if developed were noted. Assessment included best corrected visual acuity, wound status, intraocular pressure (IOP), fundus examination and B-scan ultrasonography. Final visual acuity was graded according to World Health Organization (WHO) visual impairment categories: e" 20/70, (good visual outcome), $<20 / 70-20 / 200,<20 / 200-20 /$ $400,<20 / 400$ (low visual outcome).

\section{RESULTS}

Table 1: Shows sex and Socioeconomic status of the participants.

\begin{tabular}{|l|c|c|}
\hline & Number & $\%$ \\
\hline Male & 23 & 46.94 \\
\hline Female & 26 & 53.06 \\
\hline Low Socioeconomic status & 38 & 67.35 \\
\hline Middle Socioeconomic status & 11 & 26.53 \\
\hline
\end{tabular}

Table 2: Shows the cause of trauma for the participants who had trauma as cause of corneal blindness.

\begin{tabular}{|l|c|c|}
\hline \multicolumn{1}{|c|}{ Cause of trauma } & Number & $\%$ \\
\hline Flying/thrown objects & 14 & 28.57 \\
\hline vegetable matter & 12 & 24.49 \\
\hline Fall & 5 & 10.2 \\
\hline Tools & 5 & 10.2 \\
\hline chemicals & 5 & 10.2 \\
\hline Explosive & 4 & 8.16 \\
\hline Others & 4 & 8.16 \\
\hline
\end{tabular}

Table 3: Shows the corneal blindness.

\begin{tabular}{|c|c|c|}
\hline corneal blindness & Number & $\%$ \\
\hline One eye & 12 & 24.49 \\
\hline Both eyes & 5 & 10.2 \\
\hline
\end{tabular}

\section{DISCUSSION}

Present study conducted in the department of ophthalmology of Raichur institute of Medical sciences teaching Hospital, with 49 patients of ocular trauma above 14 years of either sex was subjected to slit lamp examination to ensure the 
cornea is involved the etiology of the injury was noted. Then the pattern of the corneal injury would be studied under the slit lamp examination.

Total 49 patients were fulling the inclusion criteria and participated in the study, 26 (53.06\%) were females, and 23 (46.94\%) were males. Due to the low Socioeconomic status people are not having sufficient knowledge on the care on corneal injury so they are high percentage $67.35 \%$ (38) it is low in Middle Socioeconomic status $26.53 \%(11)$ as shown in table 1 . The major cause of trauma $28.57 \%$ (14) was due to flying or thrown objectives like while cutting of wood, stone, in the violence, vegetable matter $24.49 \%$ (12). Trauma due to fall, tools, and chemicals share is $10.20 \%(5)$ each. Explosive and other causes share is 8.16 (4) was low but not negatable were represented in the table no. 02 . The Prevalence of corneal blindness was $10.20 \%$ (5) were had corneal blindness in both eyes and $24.49 \%$ (12) were had corneal blindness in one eye showed in the table no.03.

M.P. UPADHYAY et al studied in 2 years with the help of 81 primary eye care workers, there were 1248 cases of ocular trauma reported and 551 cases of corneal abrasion. The number of clinically documented corneal ulcers was 558. Ocular trauma and corneal ulceration are serious public health problems that are occurring in epidemic proportions at Bhaktapur [4].

R. Dandona et al. found in Andhra Pradesh, Corneal blindness in at least one eye was present in 86 participants, an age, sex, and urban-rural distribution adjusted prevalence of $0.66 \%$ ( $95 \%$ confidence interval 0.49 to 0.86 ), which included $0.10 \%$ prevalence of corneal blindness in both eyes and $0.56 \%$ in one eye. The most frequent causes of corneal blindness in at least one eye included keratitis during childhood (36.7\%), trauma (28.6\%), and keratitis during adulthood (17.7\%). Nearly $95 \%$ of all corneal blindness was avoidable. There is a significant burden of corneal blindness in this population, the majority of which is avoidable [9].

Gullapalli N. Rao et al. studied that Ocular trauma is responsible for $1 \%$ to $10 \%$ of corneal blindness. The geographic location, pattern of injury, causative agent, and age are some of the factors that determine the degree of damage [10]. In urban areas and in the industrialized world, chemical injuries, accidents at the workplace, and automobile injuries are common. In rural areas of developing countries, minor trauma due to hazardous practices in agriculture, cottage industries, and other work places, as well as sports accidents, are responsible for a large proportion of corneal blindness [11].

In spite of natural protection to eyes, injuries to globe do occur, frequently, the potentially devastating from the point of view of visual function. The majority of these injuries are sustained by active and productive individuals unfortunately, these injuries may all be often vision threatening and the life style and future of these injured individuals are irrevocably altered. Looking at the present scenario of working pattern and visual demands of patients and the use of sophisticated instruments, it has become mandatory on the part of an ophthalmologist to identify the various ocular structures involved due to blunt trauma, which may vary in severity from a simple corneal abrasion to an extensive rupture of globe, and provide satisfactory vision at its earliest of blunt injuries in a total perspective. Closed-globe injuries are more common than open globe injuries [4].

\section{CONCLUSION}

Corneal injuries remain an important cause of avoidable and, predominantly, monocular visual morbidity, the main strategy to prevent these injuries has been to educate people to identify high-risk situations and to take correct action to avoid danger. Eye health promotion strategies are warranted to raise awareness about the causes and prevention of corneal blindness.

\section{REFERENCES}

[1]. Desai P, MacEwen CJ, Baines P, Minassian DC.Department of Public Health and Policy, London School of Hygiene and Tropical Medicine; Incidence of cases of ocular trauma admitted to hospital and incidence of blinding outcome. Br J Ophthalmol. 1996;80(7):592-6.

[2]. CHU Jean-Minjoz de Besançon, université de FrancheComté, 3, boulevard Fleming, 25030 Besançon, France. msaleh@chu-besancon.fr J Fr Ophtalmol. 2012;35(6):445-53.

[3]. Thylefors B, Negrel Ad, Pararajasegaram R, And Dadzie Ky: Global Data On Blindness 1995 Bull Who 72:115. 
[4]. M P upadhyay, P C karmacharya, S koirala, D N shah, S shakya, J K shrestha, et al. the Bhaktapur eye study: ocular trauma and antibiotic prophylaxis for the prevention of corneal ulceration in nepal, British journal of ophthalmology 2001; 85:388-92.

[5]. S K Khatry, A E Lewis, O D Schein, M D Thapa, E K Pradhan, J Katz: the epidemiology of ocular trauma in rural Nepal. British Journal of Ophthalmology. 2004; 88: 456-60.

[6]. Whitchar JP, Srinivasan M, Upadhayay MP. Corneal blindness: a global perspective. Bull World Health Organ. 2001;79:214-21.

[7]. Leck A K, Thomas PA, Hagan M, Kaliamurthy J, Ackuaku $E$, John $M$, et al. Aetiology of suppurative corneal ulcers in Ghana and south India, and epidemiology of fungal keratitis. Br J Ophthalmol. 2002;86:1211-15.
[8]. Robert C. Arff, Grayson's Diseases of the Cornea, 4th edition, Mosby Publications, p257-269

[9]. R Dandona, L Dandona: Corneal Blindness In A Southern Indian Population: Need For Health Promotion Strategies British Journal Of Ophthalmology. 2003; 87:133-141.

[10]. Adapted From World Health Organization: Report Of The International Meeting On Control Of Corneal Blindness Within Primary Health Care Systems. Geneva, Who, 1988, Pp 1-22.

[11]. Gullapalli N. Rao: Corneal Opacification In The Developing World Chapter 61.

How to cite this article: Srividya $\mathrm{R}, \mathrm{H}$. Siddesh Kumar. A STUDY OF CORNEAL INJURIES IN RIMS TEACHING HOSPITAL. Int J Intg Med Sci 2019;6(4):826-829. DOI: 10.16965/ijims.2019.115 